Çukurova Üniversitesi Mühendislik Mimarlık Fakültesi Dergisi, 32(4), ss. 21-30, Aralık 2017

Çukurova University Journal of the Faculty of Engineering and Architecture, 32(4), pp. 21-30, December 2017

\title{
Çimento Hammadde Sahasının Bulanık Sinir Ağı ile Modellenmesi
}

\author{
Faruk ŞAHİN ${ }^{1}$, Ahmet DAĞ ${ }^{* 1}$, Bayram Ali MERT ${ }^{2}$ \\ ${ }^{1}$ Çukurova Üniversitesi, Mühendislik Mimarlık Fakültesi, Maden Mühendisliği Bölümü, Adana \\ ${ }^{2}$ İskenderun Teknik Üniversitesi, Mühendislik ve Doğa Bilimleri Fakültesi, Petrol ve Doğalgaz \\ Mühendisliği Bölümü, Hatay
}

Geliş tarihi: 09.05.2017_ Kabul tarihi: 19.12.2017

$\ddot{\mathbf{O z}}$

Çimento üretiminde hammaddenin kimyasal kompozisyonu üretim işlemlerini ve çimentonun kalitesini etkileyen önemli bir faktördür. Kireç Doygunluk Faktörü (KDF) çimento sanayinde kullanılan kimyasal modüller arasında kritik olanıdır. Kimyasal bileşenler kullanılarak bu değerin kestirilmesi klinker üretimi öncesi önem kazanmaktadır. Bu çalışmada, özellikle mühendislik çalışmalarında önem kazanan esnek hesaplama tekniklerinin çimento sektöründe kullanılabilirliği araştırılmıştır. Bu amaçla Adana Çimento hammadde sahası için kireç doygunluk faktörü dağılımının tahmini bulanık sinir ağları yöntemi ile gerçekleştirilmiştir. Sonuç olarak, yapılan çalışmalar başarılı tahminlerin yapıldığını göstermiş ve çimento endüstrisinde esnek hesaplama teknikleri güçlü ve esnek model yapılarının sağlanmasında uygun araçlar olarak değerlendirilebilir.

Anahtar Kelimeler: ANFIS, Esnek hesaplama, Kireç doygunluk faktörü

\section{Modelling of Cement Raw Material Site using Fuzzy Neural Network}

\begin{abstract}
The chemical composition of raw materials is an important factor that affects the production process and the quality of cement. Lime Saturation Factor (KDF) is one of the critical used in the cement industry between chemical modules. Prediction of this value using chemical components is gaining importance in pre clinker production. In this study, it is investigated that usage of soft computing techniques which have been popular particularly in engineering works. For this purpose, the prediction of lime saturation factor distributions of Adana Cement raw material site by means of fuzzy-neural network techniques has been conducted. As a consequence, the studies showed that the predictions are successful for the raw materials site and it could be accepted that soft computing techniques are convenient tools for obtaining robust and flexible model structures.
\end{abstract}

Keywords: ANFIS, Soft computing, Lime saturation factor

*Sorumlu yazar (Corresponding author): Ahmet DAĞ,ahmdag@cu.edu.tr 


\section{GíRiş}

Günümüzde çimento endüstrisi gerek üretim kapasitesi, gerek ürün kalitesi açısından önemli gelişmeler göstermektedir. Ürün kalitesi belirleme sürecinde kalite kontrol, standartlaşma ve hammadde hazırlama sektörün üretim faaliyetlerinin önemli bir parçası haline gelmiştir. Hammadde hazırlamanın ana amacı uygun kimyasal öğelere sahip homojen bir ham karışım üretmektir. Eğer hammadde ocağının kalite oranlarının ortalama değerleri önemli farklılıklar göstermiyorsa malzemenin homojen olduğu söylenebilir. İstenilen ürün kalitesi hammaddenin ocaktan çıkarılmasından, ürünün paketlenmesi aşamasına kadar bütünsel bir denetim planının hazırlanmasıyla başarılabilir [1].

Genelde amaç, mümkün olduğu kadar yüksek $\mathrm{C}_{3} \mathrm{~S}$ içerikli bir klinker üretmektir. $\mathrm{Bu}$, mevcut malzemenin toplam kompozisyonuna ve işletme koşullarına bağlı olan bir husustur. $\mathrm{Bu}$ potansiyel kireç doygunluk faktörü cinsinden ifade edilir.

$$
\mathrm{KST}=\frac{100 \mathrm{CaO}}{2.8 \mathrm{SiO}_{2}+1.18 \mathrm{Al}_{2} \mathrm{O}_{3}+0.65 \mathrm{Fe}_{2} \mathrm{O}_{3}}
$$

Hammadde karışımının en önemli bileşeni olan $\mathrm{CaO}$ miktarının çok dikkatle hesaplanması önem arz etmektedir [2].

Çimento hammadde sahasının kalite dağılımının bilinmesi de hammadde homojenliğinin sağlanması açısından önemlidir. Hammadde sahasındaki formasyonlara ait kalite değerlerinin kestirimi hem optimum üretim planlaması ile harmanlama hem de yatırımların planlanmasında büyük olanaklar sağlayacaktır. Son yıllarda, esnek hesaplama ve yapay zeka tekniklerinde ki hılı gelişmeler çeşitli hesaplama tekniklerinin (bulanık mantık, sinir ağları gibi) madencilikte de kestirim amaçlı uygulama alanı bulmasını sağlamıştır [3-5]. Çimento sektöründe ise gerek fabrika ölçeğinde ve gerekse de saha ölçeğinde kestirime dayalı çalışmalar yapılmıştır. $\mathrm{Bu}$ çalışmalarda blaine (serbest yüzey) ve kimyasal içerikler, regresyon ve ileri yöntemlerle kestirilmiştir [6-8].
Bu çalışmada, Adana Çimento hammadde sahasına ait sondaj bilgilerinden önemli bir hammadde parametresi olan Kireç Doygunluk Faktörü (KDF) esnek hesaplama yöntemlerinden bulanık sinir ağları modelleme algoritması ile kestirilmiş ve sonuçlar değerlendirilmiştir. Esnek modellemeye olanak tanıyan bulanık mantık teorisinin yapay sinir ağlarına adaptasyonun, öğrenmeye dayalı bir model yapısıyla başarılı sonuçlar elde edilmesini sağlamaktadır.

\section{CALIŞMA ALANI}

Çimento hammadde sahası kalite dağılımının belirlenmesi için Adana Çimento Sanayii T.A.Ş' ye ait hammadde sahasının sondaj bilgileri kullanılmıştır. Fabrika ve hammadde ocak sahası Adana-Ceyhan Karayolu 12. km İncirlik mevkiinde olup, klinker üretim ünitesiyle aynı saha içerisinde yer almaktadır (Şekil 1).

\section{METOD}

Bulanık Sinir Ağları yaklaşımı, yapay sinir ağlarının öğrenme yeteneği, en uygunu bulma ve bağlantı yapılar gibi, özellikleriyle bulanık mantığın insan gibi karar verme ve uzman bilgisi sağlama kolaylığı gibi üstünlüklerinin birleştirilmesi temeline dayanmaktadır. Bu yolla, bulanık denetim sistemlerine, sinir ağlarının öğrenme ve hesaplama gücü verilebilirken, sinir ağlarına da bulanık denetimin insan gibi karar verme ve uzman bilgisi sağlama yeteneği kazandırılmaktadır.

Bulanık Sinir Ağlarının asıl amacı, sinirsel bulanık denetim sistemlerinin yapısını, değişkenlerini ayarlamak için sinir ağları öğrenme tekniklerini uygulamaktır. Bulanık mantık denetleyicilerde yapısal ve değişken ayarlama olmak üzere iki önemli ayarlama gerekir [9-10].

Hammadde sahası Kireç Doygunluk Faktörü dağılımının modellenmesinde son yıllarda yoğun olarak kullanılan ve güçlü bir sistem olan ANFIS (Adaptive Neuro Fuzzy Inference System) sinirsel bulanık çıkarım sistemi kullanılmıştır. 


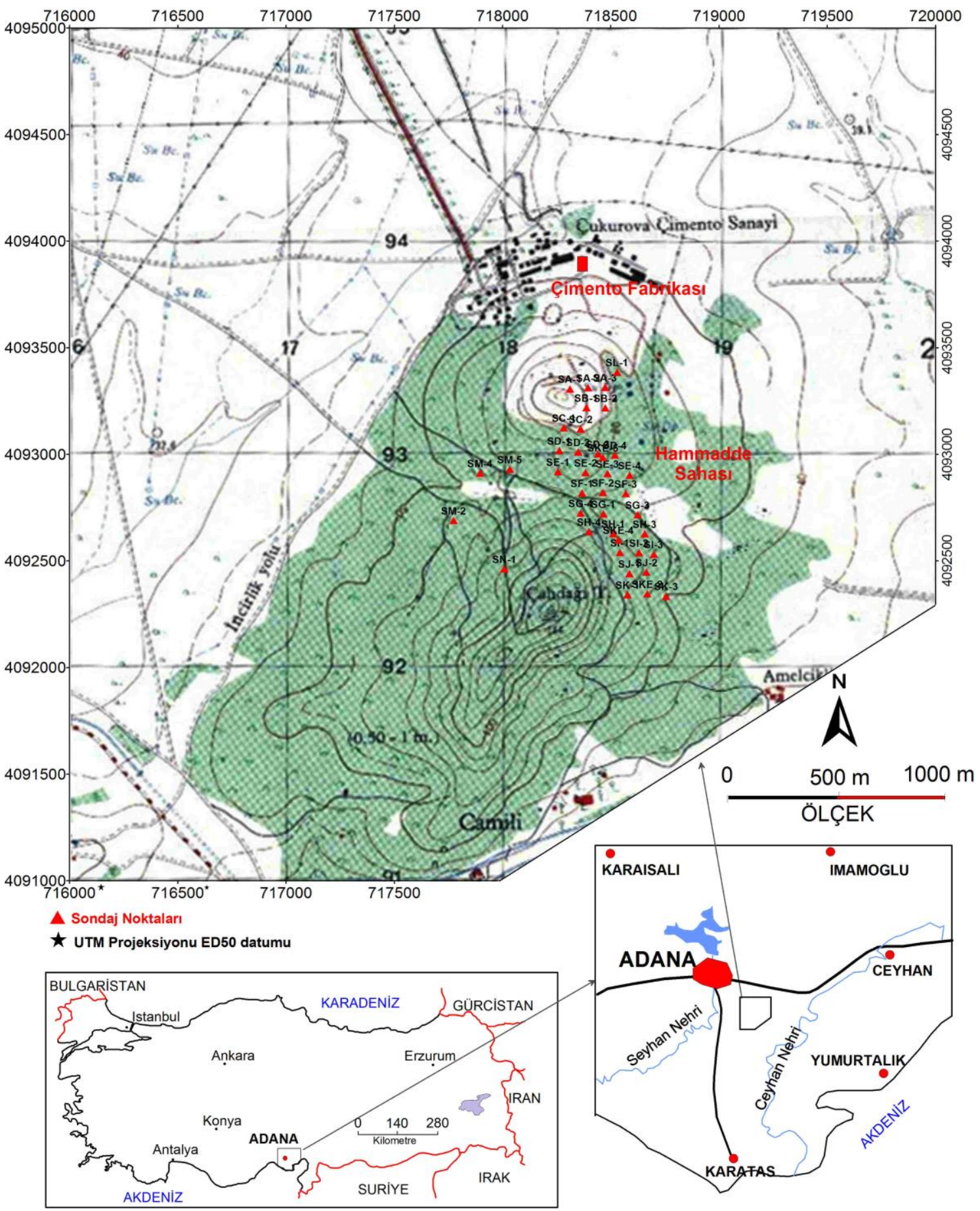

Şekil 1. Çalışma alanı yer bulduru haritası 


\subsection{Uyarlamalı A $\breve{g}$ Esaslı Bulanık Çıkarım Sistemi (ANFIS)}

Bulanık çıkarım sistemleri ve çok katmanlı yöntemler uyarlamalı ağların genel hesaplama çalışmalarının örnekleridir. Her iki örnekte uyarlamalı ağın geriye yayılma öğrenme yeteneğini almıştır. ANFIS uyarlamalı ağların, işlevsel olarak bulanık çıkarım sistemine eşdeğer olan bir sınıfıdır. TSK ise Sugeno bulanık modeli veya Takagi, Sugeno, Kang bulanık mantık modeli anlamında kullanılmaktadır. Aynı şekilde karma sinir ağları olarak da bilinmektedir.

Aslında bulanık çıkarım sistemi çok katmanlı yöntemlere göre daha kuvvetlidir. Örnek olarak ANFIS denetleyicilerin bazı önemli özellikleri tanımlanabilir.

1. Öğrenme yeteneği,

2. Paralel işlem,

3. Yapılandırılmış bilgi temsili,

4. Diğer denetim tasarım yöntemleri ile bütünleşme

Çok katmanlı yöntemler 1. ve 2. özelliklere sahiptir ama 3. ve 4. özelliklere sahip değildir.

ANFIS'in yapısındaki bulanık çıkarım sisteminin mimarisinin kolaylıkla anlaşılabilmesi için $\mathrm{x}$ ve $\mathrm{y}$ olmak üzere iki girişi ve f gibi bir çıkışı olduğu kabul edilirse, Birinci Derece Sugeno bulanık modeli için iki bulanık 'EĞER-O HALDE' kuralı Eşitlik (2)'deki gibi olur [11].

Kural 1: EĞER $x=A_{1}$ ve $y=B_{1}$ ise

$\mathrm{O}$ HALDE $f_{1}=p_{1} x+q_{1} y+r_{1}$

Kural 2: EĞER $x=A_{2}$ ve $y=B_{2}$ ise

$\mathrm{O}$ HALDE $f_{2}=p_{2} x+q_{2} y+r_{2}$

Eşitlikleri $\mathrm{i}=1,2$ için, $\mathrm{x}$ ve $\mathrm{y}$ giriş değişikliklerini, $f_{j}$ çıkış değişkenini, $A_{i}$ ve $B_{i}$ bulanık kümleri $p_{i}, q_{i}$, $r_{i} \in R_{i}$ olmak üzere sonuç değişkenleridir. Şekil 2'de iki girişli ve iki kurallı Sugeno tip bulanık çıkarım yöntemi verilmiştir [12].

\subsubsection{ANFIS Mimarisi}

Şekil 3'de iki girişli ve iki kurallı Sugeno tip bulanık çıkarım yöntemine eşdeğer olan ANFIS mimarisi görülmektedir. ANFIS mimarisi içerisindeki, her katmana ait bağlantı işlevleri ve katmanların işlevleri sırasıyla aşağıda verilmiştir [13].

1. Katman: bu kademedeki her bağlantı giriş sinyallerinin diğer katmanlara aktarıldığı giriş bağlantılarıdır. $\mathrm{Bu}$ bağlantıda herhangi bir toplam ya da etkinlik işlevi kullanılmamaktadır.

2. Katman: bu katmandaki her bir bağlantı $A_{i}$ ve $\mathrm{B}_{\mathrm{i}}$ gibi bir bulanık kümeyi ifade eder. $\mathrm{Bu}$ katmandaki bağlantıların çıkışı giriş örneklerine ve kullanılan üyelik işlevine bağlı olan üyelik dereceleridir. $\mathrm{Bu}$ bağlantılardan elde edilen üyelik dereceleri veya bağlantı çıkışları (3) eşitliğindeki gibidir.

$$
\begin{gathered}
o_{i}{ }^{2}=\mu_{A}(x) \\
\mathrm{i}=1,2 \ldots \ldots \mathrm{n} \\
o_{i+2}^{2}=\mu_{B}(y)
\end{gathered}
$$

(4) eşitliğinde görüldüğü gibi iki farklı bağlantı çıkışı yazılmıştır. Bunun nedeni ağın x ve y gibi iki faklı girişe sahip olmasıdır. Bu katmanda her iki giriş için toplam 4 bağlantı vardır. Her bağlantıda üyelik işlevi olarak en çoğu 1 ve en azı 0 olan çan eğrisi üyelik işlevleri kullanılır ve sonuç işlevi (5) eşitliğinde verilmiştir.

$$
\mu_{A i}(x)=\frac{1}{1+\left|\frac{x-m_{i}}{\sigma_{i}}\right|^{2}}
$$

$$
\mu_{A i}(x)=\exp \left[-\left(\frac{x-m_{i}}{\sigma_{i}}\right)^{2}\right]
$$

Burada ve çan eğrisi şekilli üyelik işlevinin sirasiyla orta noktasinı ve standart sapmasinı gösterir. Bu değişkenler ağ eğitilirken ayarlanır. 


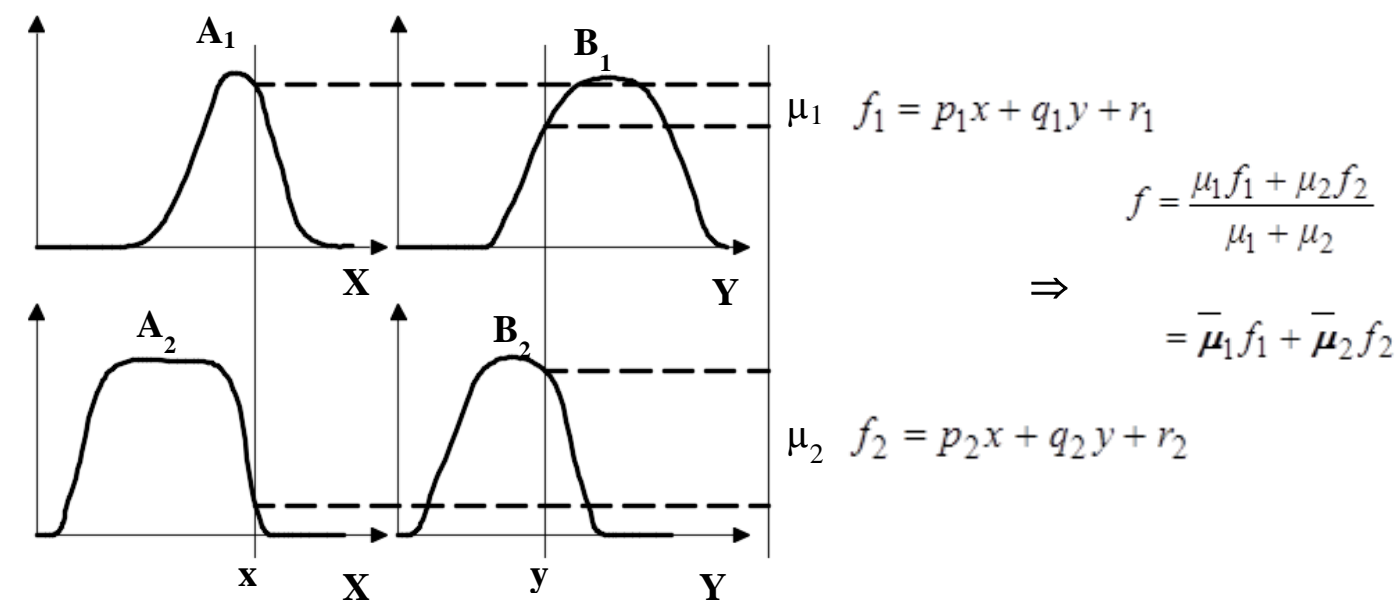

Şekil 2. İki girişli ve iki kurallı Sugeno tip bulanık çıkarım [12]

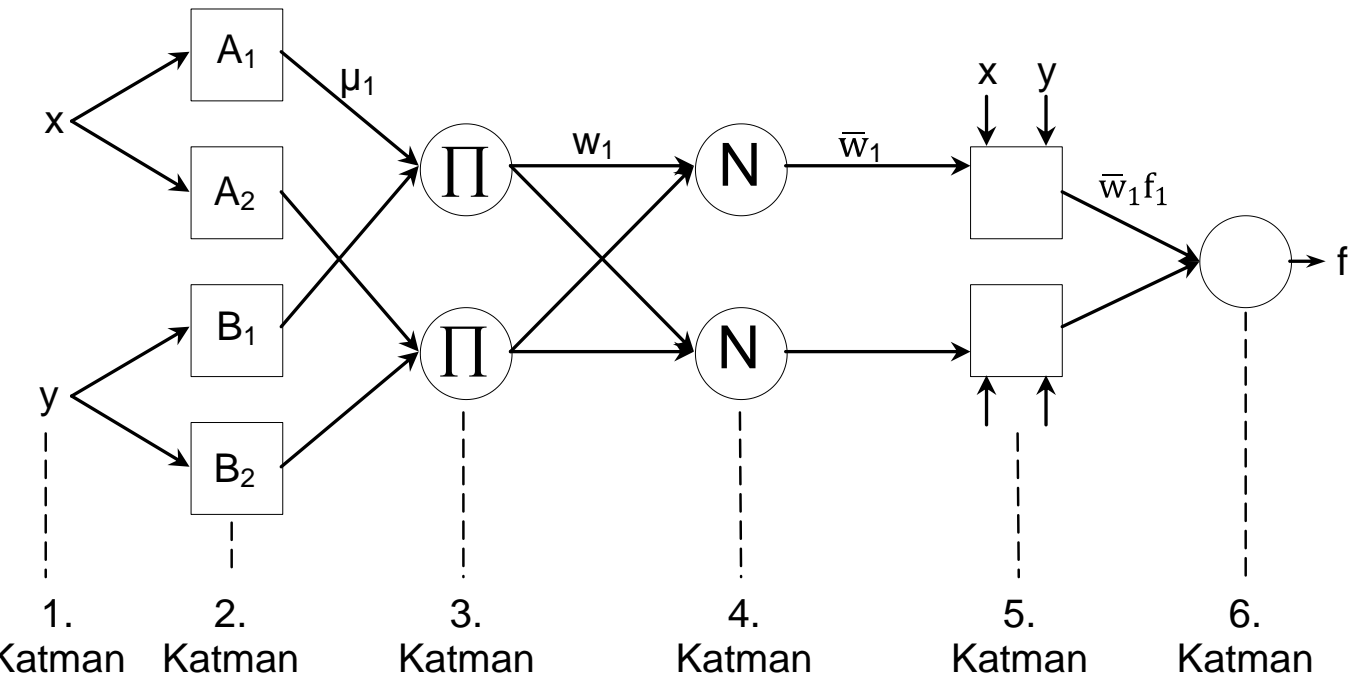

Şekil 3. İki girişli ve iki kurallı Sugeno tip bulanık çıkarıma eşdeğer ANFIS mimarisi [13]

3. Katman: $\mathrm{Bu}$ katmandaki her bağlantı, $\Pi$ ile etiketlenmiştir ve giren tüm işaretlerin çarpımını gösterir. Bağlantı çıkışı (6) eşitliğindeki gibi ifade edilebilir.

$o_{i}^{3}=\mu_{i}=\mu_{A_{i}}(x) \mu_{B_{i}}(y) ; i=1,2, \ldots \ldots n$

Her bir bağlantının çıkışı bir kuralın tetikleme seviyesini temsil eder genelleştirilmiş bulanık VE'yi yerine getiren t-norm operatörlerden herhangi biri, bu katmandaki bağlantılar için bağlantı işlevi olarak kullanılabilir.

4. Katman: $\mathrm{Bu}$ katmandaki her bağlantı $\mathrm{N}$ ile etiketlenmiştir ve bir kuralın normalleştirilmiş tetikleme seviyesi hesaplanır. Bu (7) eşitliğinde görüldüğü gibi i. bağlantı için, i. kurala ait tetikleme kuvvetinin tüm kuralların tetikleme kuvvetlerinin toplamına oranını bulur. Yani i. kurala ait tetikleme kuvveti normalize edilir. 
$o_{i}^{4}=\overline{\mu_{i}}=\frac{\mu_{i}}{\mu_{1+} \mu_{2}}, i=1,2 \ldots \ldots n$

5. Katman: Bu katmandaki her i bağlantı, bağlantı işlevi ile uyarlamalı bir bağlantıdır. Her i bağlantı sonuç ağırlıkları değerlerini hesaplar. Bağlantı çıkış işlevi (8) eşitliğindeki gibi yazılabilir.

$o_{i}^{5}=\bar{\mu}_{i} f_{i}=\bar{\mu}_{i}\left(p_{i} x+q_{i} y+r_{i}\right)$

Burada $\mu \mathrm{i}$ 4. Katmanın çıkışıdır ve normalleştirilmiş tetikleme seviyesidir ve (pi, qi, ri) ayarlanabilmesi için gerekli olan, ayar değişken kümesidir. $\mathrm{Bu}$ katmandaki değişkenler sonuç değişkenlere karşılık gelir.

6. Katman: Bu katmanda sadece bir bağlantı vardır ve $\Sigma$ ile etiketlenmiştir. Burada, 5. Katman çıkışından alınan sinyaller toplanır ve elde edilen sonuç sistemin gerçek çıkışı f değerini verir. Ağın gerçek çıkış1 (9) eşitliğinde verilmiştir.

$o^{6}=f=\sum_{i} \overline{\mu_{i}} f_{i}=\frac{\sum_{i} \mu_{i} f_{i}}{\sum_{i} \mu_{i}}$

Böylece Sugeno bulanık çıkarım modeline işlevsel olarak eşdeğer olan, örnek ANFIS yapısı tanımlanmıştır. Ağın yapısı tamamen sabit değildir. Ağın oluşturulması ve bağlantı işlevlerinin görevlerine göre ayrılması, her katmandaki her bir bağlantının sağladıklarına ve modüler işlevselliğine göre keyfi olarak seçilebilir.

Bütün sonuç değişkenler bir vektör olarak $\left(\mathrm{p}_{1}, \mathrm{q}_{1}, \mathrm{r}_{1}, \mathrm{p}_{2}, \mathrm{q}_{2}, \mathrm{r}_{2}\right) \mathrm{T}$ şeklinde düzenlenir ve (10) eşitliğindeki eşitlik ile gösterilebilir.

$$
\mathrm{f}=\left[\overline{\mu_{1}} \overline{\mu_{1}} \mathrm{x} \overline{\mu_{1}} \mathrm{y} \overline{\mu_{2}} \overline{\mu_{2}} \times \overline{\mu_{2}} \mathrm{y}\right]\left[\begin{array}{c}
\mathrm{r}_{1} \\
\mathrm{p}_{1} \\
\mathrm{q}_{1} \\
\mathrm{r}_{2} \\
\mathrm{p}_{2} \\
\mathrm{q}_{2}
\end{array}\right]
$$

Sonuç ve üyelik işlevlerine ait değişkenlerin ayarlanmasında geri yayılımlı öğrenme algoritması kullanılabilir. Şekil 4'te verilen ANFIS için gerekli eğitim algoritması aşağıda verilmiştir.

\subsubsection{ANFIS için Geri Yaylımlı Öğrenme Algoritması}

ANFIS sisteminin parametrelerini belirlemek için geri yayılımlı bir öğrenme algoritması kullanılır. Ağ parametrelerinin optimizasyonu için geri yayılımlı öğrenme algoritması eğim düşüm (gradient descent) ve en küçük kareler (least square) tekniklerini kullanır. Önerilen bu yaklaşımda, sistemin çıktıları $(f)$ Eşitlik (11)'de verilmiştir [14].

$$
\begin{aligned}
f= & \frac{\mu_{1}}{\mu_{1}+\mu_{2}} f_{1}+\frac{\mu_{2}}{\mu_{1}+\mu_{2}} f_{2}=\bar{\mu}_{1} f_{1}+\bar{\mu}_{2} f_{2} \\
= & \left(\bar{\mu}_{1} x\right) p_{1}+\left(\bar{\mu}_{2} y\right) q_{1}+\left(\bar{\mu}_{1}\right) r_{1}+\left(\bar{\mu}_{2} x\right) p_{2}+ \\
& \left(\bar{\mu}_{2} y\right) q_{2}+\left(\bar{\mu}_{2}\right) r_{2}
\end{aligned}
$$

Geri yayılımlı öğrenmeye dayalı çalışmalar hızlı ve etkin çözümleme yapıldığını göstermektedir. Anfis bu çözümü doğrusal sistem çıktısıyla ortaya koymaktadır [15].

\section{UYGULAMA}

\subsection{Hammadde Verilerinin Değerlendirilmesi}

Hammadde sahasının dağılımının modellenmesi için gerekli olan Kireç Doygunluk Faktörü (KDF) verileri, daha önce sahada yapılmış olan 39 adet sondaja ait bilgilerinden elde edilmiştir. Sondajların kestiği formasyonlara ait kimyasal analizlerden her bir sondaj lokasyonuna ait KDF değerleri ağırlıklı ortalamaları alınarak belirlenmiştir. $\mathrm{Bu}$ şekilde elde edilen hammadde sahasına ait KDF kalite parametresi tanımlayıcı istatistiki bilgileri Çizelge 1'de belirtilmiştir.

\subsection{Hammadde Sahasının Modellenmesi}

Hammadde hazırlama öncesi sahadaki dağılımın bilinmesinde önem taşıyan önemli parametrelerden biri olan Kireç Doygunluk Faktörünün (KDF) 
kestirimi için iki girişli (Doğu, Kuzey) bir sistem kullanılmıştır. Sistem yatağın yapısına bağlı olarak belirlenen 2 kümeye eşdeğer sayıda iki kural kullanmaktadır. Dilsel değişkenler için Çan eğrisi (bell-shaped) üyelik fonksiyonun uygun olduğu değerlendirilmiştir. Modelde kullanılan başlangıç ve uyarlanmış üyelik fonksiyonları Şekil 4-7'de gösterilmektedir.

Çizelge 1. Hammadde sahası KDF parametresi istatistiksel bilgileri

\begin{tabular}{|l|c|}
\hline Parametre & Değer \\
\hline Ortalama & 181,27 \\
\hline Standart Hata & 19,71 \\
\hline Ortanca & 168,76 \\
\hline Standart Sapma & 123,09 \\
\hline Örnek Varyans & 15150,45 \\
\hline Basıklık & 2,57 \\
\hline Çarpıklık & 1,47 \\
\hline Aralık & 561,92 \\
\hline En Küçük & 22,85 \\
\hline En Büyük & 584,77 \\
\hline Veri Sayısı & 39 \\
\hline Değişim Katsayısı & 0,68 \\
\hline
\end{tabular}

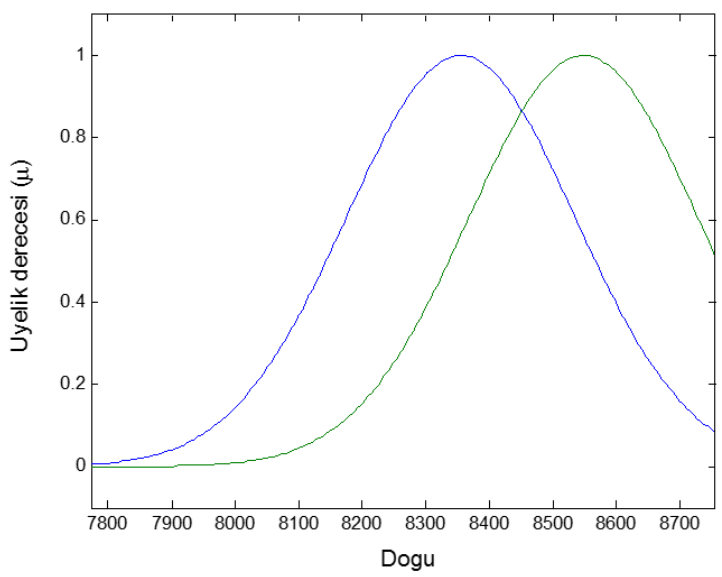

Şekil 4. Doğu parametresi için başlangıç girdi üyelik fonksiyonları

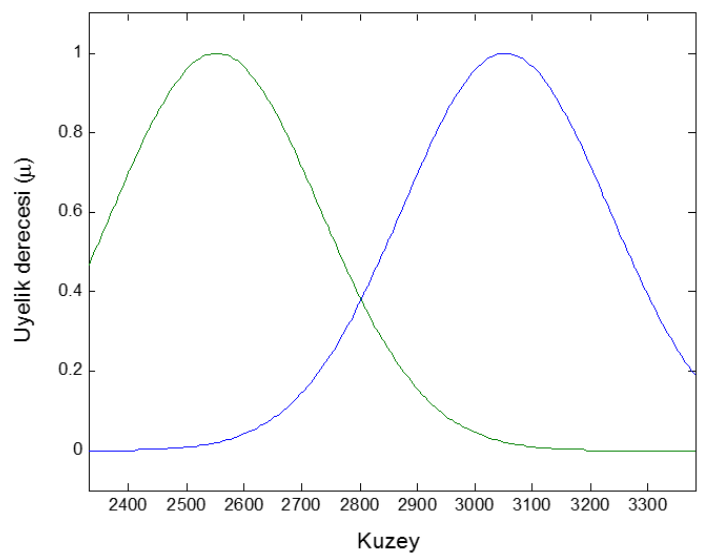

Şekil 5. Kuzey parametresi için başlangıç girdi üyelik fonksiyonları

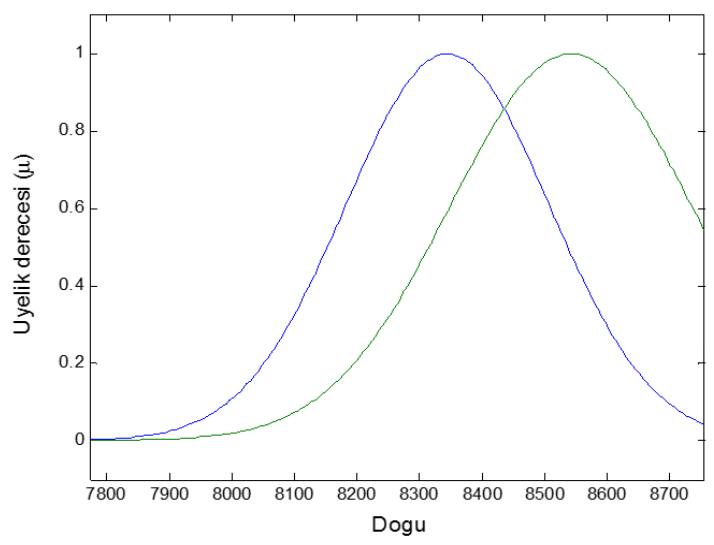

Şekil 6. Doğu parametresi için uyarlanmış üyelik fonksiyonları

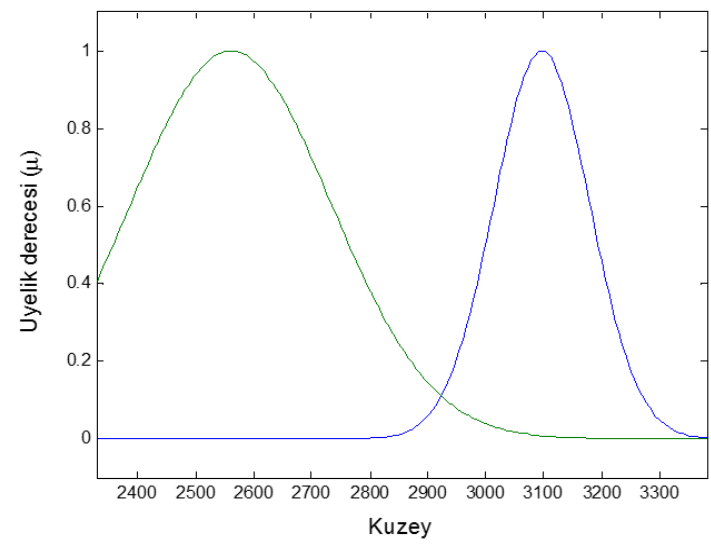

Şekil 7. Kuzey parametresi için uyarlanmış üyelik fonksiyonları 
Kullanılan sinirsel bulanık çıkarım sisteminin performansının değerlendirilmesi için ölçülen model verileri girdi olarak kullanılıp KDF değerleri kestirilmiştir. Ölçülen ve kestirilen değerler çapraz doğrulama ile incelendiğinde korelasyon katsayısının (r), 0,77 olduğu görülmüştür (Şekil 8).

Hammadde sahasında kullanılan sondajları da içerisine alan Doğu $(717770 ; 718760)$ ve Kuzey (4092330; 4093380) koordinatları ile tanımlanmış bir sektördeki KDF değerleri kestirilmiş ve elde edilen veriler ile sahanın KDF dağılım haritası Şekil 9'da verilmiştir.

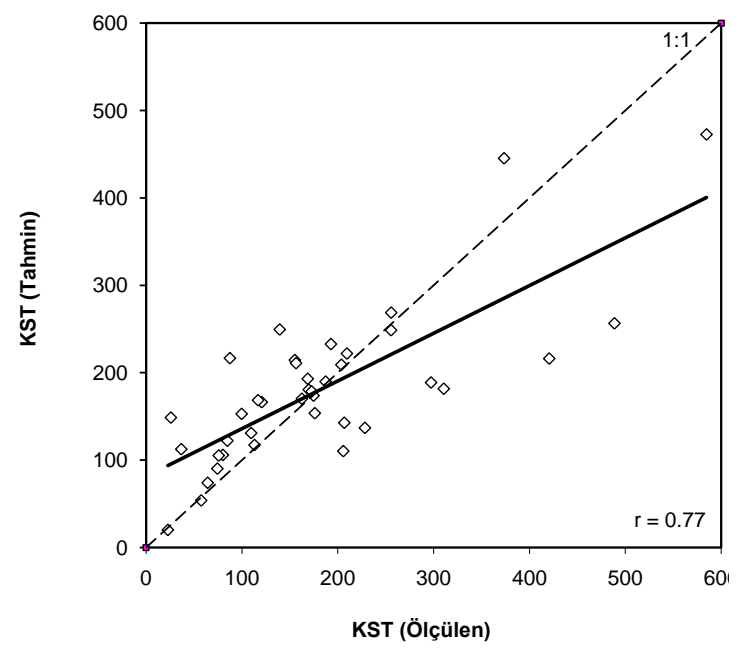

Şekil 8. KDF performansı için çapraz doğrulama grafiği

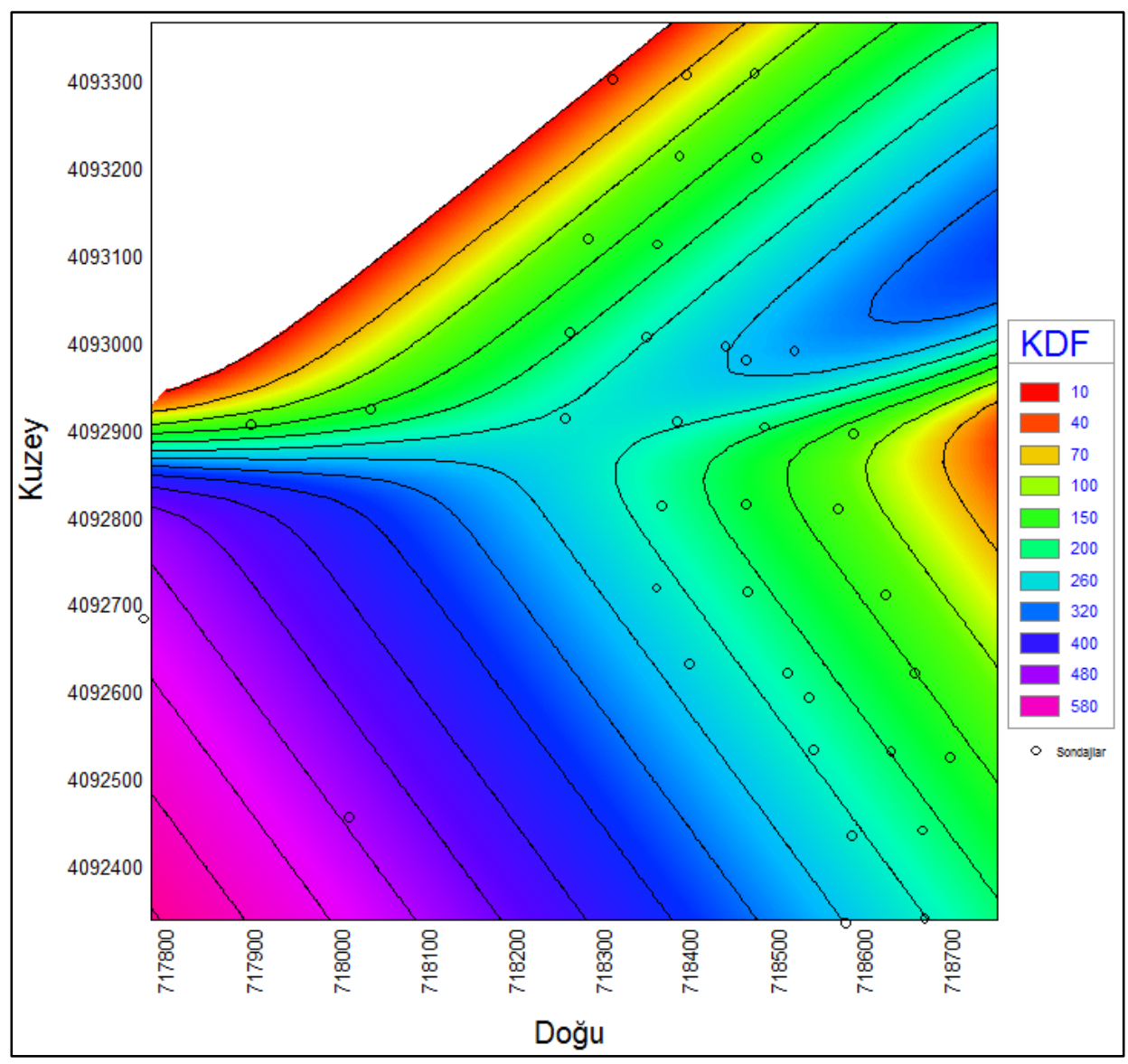

Şekil 9. Hammadde sahası KDF dağılım haritası 


\section{SONUÇLAR VE ÖNERILLER}

$\mathrm{Bu}$ çalışma ile son yıllarda yerbilimlerinde yaygın kullanım özelliği kazanan esnek hesaplama yaklaşımlarından biri olan bulanık sinir ağları esaslı model yapısıyla çalışmalar yapılmıştır. Model yap1s1 doğrudan veri sürümlü (data driven) karaktere sahip olup uyarlamalı yapısıyla sistem optimizasyonunu başarıyla yapmaktadır.

Çimento hammadde uygulama sahası için Kireç Doygunluk Faktörü (KDF) kestiriminden elde edilen sonuçlar başarı model yapılarına işaret etmektedir $(\mathrm{r}=0,77)$. Geçerli model yardımıyla kestirilen KDF değerlerinden elde edilen harita sektördeki hammaddenin kalite dağılımını göstermektedir.

Bu çalışmada kullanılan bulanık sinir ağlarıyla modelleme uygulanabilir bir yöntem olarak belirlenmesine karşın modelleme aşamalarında (özellikle kuralların oluşturulmasında) daha dikkatli olunması ve model yapısının uzmanlarca oluşturulması gerekmektedir. Ayrıca, kullanılan kestirim tekniği diğer hammadde parametrelerin (SIM, ALM, Alkali, Blane gibi) ve çimento parametrelerinin değerlendirilmesinde de kullanılabilecektir. Özellikle çimento kalite kontrol aşamalarında esnek modelinin kullanılmasının yararlı sonuçlar verebileceği öngörülebilir.

\section{KAYNAKLAR}

1. Şahin, F., 2009. Çimento Hammadde ve Üretim Sürecinde Esnek Hesaplama Yöntemlerinin Kullanımı. Yüksek Lisans Tezi, Çukurova Üniv. Fen Bilimleri Enstitüsü, Adana, 52.

2. Yalnız, H., 2006. Çimento Sanayii Hammadde

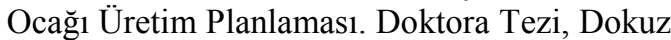
Eylül Üniv. Fenbilimleri Enstitüsü, İzmir, 182.

3. Pahm, T.D., 1997. Grade Estimation using Fuzzy-Set Algorithrns. Mathematical Geology, 29, 291-304.

4. Bardossy, G., Fodor, J., 2004. Evaluation of Uncertainties and Risks in Geology. Springer, 221.
5. Tütmez, B., Dag, A., 2007. Use of Fuzzy Logic in Lignite Inventory Estimation. Energy Sources Part B, 2, 93-103.

6. Tutmez, B. 2015. A Data-driven Study for Evaluating Fineness of Cement by Various Predictors, Int. J. Mach. Learn. \& Cyber., 6, 501-510.

7. Tutmez, B., Dag, A., 2012. Regression-based Algorithms for Exploring the Relationships in a Cement Raw Material Quarry, Computers and Concrete, 10, 5, 457-467.

8. Özdemir, A.C., Dağ, A., 2017. Çimento Sektöründe Basınç Dayanımının Esnek Hesaplama Yöntemleri ile Modellenmesi, $2^{\text {nd }}$ International Mediterranean Science and Engineering Congress, Adana, 1-6.

9. Karay, F.O., De Silva, C., 2004. Soft Computing and Intelligent Systems Design: Theory, Tools and Applications, Pearson Addison Wesley, England.

10. Buckley, J.J., Hayashi, Y., 1995. Neural Networks for Fuzzy Systems, Fuzzy Sets and Systems, 71, 265-276.

11. Takagi, H., Sugeno, M., 1983. Derivation of Fuzzy Control Rules from Human Operator's Control Actions, Proceedings of IFAC Symposium on Fuzzy Information, Knowledge Representation and Decision Analysis, 55-60.

12. Takagi, T., Sugeno, M., 1985. Fuzzy Identification of Systems and its Applications to Modelling and Control. IEEE Transactions on Systems, Man, and Cybernetics, 15, 116-132.

13. Tütmez, B., Hatipoğlu, Z., Kaymak, U., 2006. Modeling Electrical Conductivity of Groundwater using an Adaptive Neuro-Fuzzy Inference System. Computer\&Geosciences 32 (4), 421-433.

14.Jang, J., 1993. ANFIS: Adaptive NetworkBased Fuzzy Inference System. IEEE Transaction on Systems, Man and Cybernetics 23, 665-685.

15. Vahidi, E.K., Malekabadi, M.M., Rezaei, A., Roshani, M.M. 2017. Modelling of Mechanical Properties of Roller Compacted Concrete Containing RHA using ANFIS. Computers and Concrete 19(4), 435-442. 
